\title{
ASSESSING THE JOB-FINDING PROBABILITY OF OLDER AND PRIME-AGE UNEMPLOYED WORKERS ${ }^{*}$
}

\author{
Vladislav Flek ${ }^{a}$, Martin Hálaa, Martina Mysíkováa
}

\begin{abstract}
We analyse the extent and determinants of somewhat gloomy employment prospects of older unemployed populations in Austria, the Czech Republic, Poland and Slovakia. For this purpose, we explore the European Union Statistics on Income and Living Conditions over the period 2004-2014. Survival estimates suggest that older unemployed workers face lower job-finding probabilities compared to prime-age unemployed workers, while this age-based gap increases with longer unemployment spells. The results of estimating the hazard models reveal that the job-finding probability of older unemployed workers is about 20-25\% lower than that of the prime-age group, even after controlling for explanatory covariates and unobserved heterogeneity. Unemployment duration appears to be the major determinant of job-finding probability within both age groups. In contrast, the impact of explanatory covariates (gender, education, household characteristics, etc.) is relatively less robust and/or uniform.
\end{abstract}

Keywords: Hazard model, job-finding probability, older population, survival function, unemployment duration

JEL Classification: J14, J64, J71

\section{Introduction}

This paper analyses the differences in employment perspectives between the older and prime-age groups of unemployed workers. The reasons for which this issue deserves permanent research attention include macroeconomic and labour market policy considerations and challenges linked with population ageing or with the threat of age-based social polarisation.

a ŠKODAAUTO University, Mladá Boleslav, Czech Republic

Email: vladislav.flek@savs.cz,martin.hala@savs.cz,martina.mysikova@savs.cz

* The longitudinal datasets of the European Union Statistics on Income and Living Conditions (EU-SILC) were made available to the authors on the basis of the research project proposal for microdata access No. 242/2016-EU-SILC, granted to ŠKODA AUTO University by the European Commission, Eurostat. However, the authors alone, and not Eurostat, are responsible for the results presented. 
Firms tend to prefer the "reliable" (prime-age) segment of the labour force in their hiring decisions. The group of older unemployed workers is excluded, at least partly, from labour market competition, and contributes to the structural component of unemployment. This leads to equilibrium unemployment rates higher than otherwise sustainable, and to losses in potential output thereof (Blanchard, 1999).

Unemployment of older workers requires attention also in the context of population ageing. The current trend emphasizes extending working lives and penalising early withdrawals, to grapple with the consequences of ageing populations. Longer life expectancy frequently implies rises in the statutory retirement age, along with efforts to align the statutory retirement age for men and women. This, coupled with improvements in their health status, explains why the employment rate of older workers aged 55-64 in OECD countries rose from $48 \%$ in 1990 to nearly $60 \%$ in 2016 on average (Martin, 2018).

However, the hiring rates of older workers (proxied as the relative share of employees aged 55-64 with job tenure of less than one year in total employment) in OECD countries have remained just between one third and one half of the hiring rates of the prime-age cohorts (Martin, 2018). This suggests that a bias against hiring older workers still prevails, and persistence of their unemployment may undermine the desired effects of policies aimed at solving the economic and social consequences of ageing populations.

Older unemployed workers form one of major risk groups on labour markets. Their joblessness persists for extended periods because they are simply 'too old to find a job, too young to retire' (Ichino et al., 2014). Their situation typically requires targeted policy interventions, aimed to limit the likelihood of marginalisation, poverty, social exclusion, family problems, and negative impacts on mental and physical well-being, to name a few of the adverse consequences of prolonged unemployment spells.

Unemployment of older workers deserves additional attention particularly in countries with a relatively brief history of market economy, where this research direction remains rather underexplored. Our focus is on the Czech Republic, Poland, and Slovakia, while Austria represents a highly developed reference economy, with well-functioning labour market policies and welfare system. We concentrate on unemployed workers aged 50-61 at the beginning of our investigation, and compare their results with those of a group of prime-age unemployed workers aged 35-49 over the period 2004-2014. For this purpose, we explore the European Union Statistics on Income and Living Conditions (EU-SILC).

The Czech Republic is often heralded as a safe low-unemployment harbour. Apart from other findings, it is worth noting that the employment rate for the age-group 55-64 approached $60 \%$ in 2016, and was some 10-15 percentage points higher than the corresponding rates in the remaining countries covered by our analysis. However, a closer look reveals than the hiring rate of older workers in the Czech Republic represented 
a mere $6 \%$, as compared with the OECD average of $9 \%$. The hiring rate for Czech older workers is comparable with that for Austria, but remains slightly lower than those recorded for Poland or Slovakia (Martin, 2018).

Moreover, during the boom period 2004-2007, more older Czech workers had lost their jobs and entered the pool of unemployed, compared to the amount of those who had left unemployment and moved into employment. Such a result (and above all its counter-cyclical character) was unique among the group of Central European countries (Flek and Mysíková, 2015). In the recessionary period 2009-2012, older Czech workers were relatively more exposed to unemployment than the remaining age groups; another exceptional result in the region (Flek et al., 2018). All this suggests that the situation of older unemployed workers requires research and policy attention even in low-unemployment countries such as the Czech Republic.

Despite the fair amount of evidence collected so far (see next section for more detail), we believe that more in-depth research is still needed, to detect the extent and determinants of the somewhat gloomy employment prospects of older unemployed workers. Our research questions concentrate on the following key issues, which have remained rather unaddressed by the previous comparative research of formerly centrally planned Central European economies:

- How deep is actually the gap in job-finding probability between the prime-age and older groups of unemployed individuals (with/without controls for potentially relevant explanatory variables other than age)?

- Do these age-based gaps vary considerably across the countries?

- How is the job-finding probability (of both age groups) evolving with increasing unemployment duration?

Answers to these questions intend to add some new and more detailed empirical background to policy debates in the areas noted above. The remainder of this paper is organised as follows: The next section offers a discussion of relevant conceptual issues in the light of related literature. Then, we describe how we conduct cross-national analyses from the longitudinal EU-SILC datasets and outline our estimation strategies. The next section reports our results, while the final one concludes the paper.

\section{Conceptual Discussion}

Our analytical intentions are rooted in the concepts of labour market segmentation (Reich et al., 1973), job market signalling (Spence, 1973) and statistical discrimination (Phelps, 1972). The workforce is fragmented according to various characteristics (including age), with different groups occupying uneven positions on the labour market. Higher age 
is explored as a negative signalling device that helps employers distinguish "low-productivity" workers from "high-productivity" workers, with the emergence of the older population as a discriminated group.

With increasing unemployment duration, their job-finding perspectives further deteriorate due to discouragement from further searches, breached contacts with social networks, and being stigmatised by potential employers as having eroded work skills and discipline. Long-term unemployment of older individuals is typically a result of both discouragement and stigmatisation, while these factors reinforce each other and it is rather hard to separate them in a rigorous manner. In any case, many older unemployed persons would reach the threshold over time and stop searching completely (Blanchard, 1999).

Some general perceptions explain the gradually increasing job displacement rates among older workers and their higher risks of long-term unemployment, including human capital obsolescence, deterioration of cognitive and learning skills, dwindling physical strength, poor health, and the low future returns associated with investments in their training and knowledge development (Eurofound, 2012; Beckes-Gellner and Schneider, 2012; Laditka and Laditka, 2016). These stereotypes prevail despite the often inconclusive empirical studies relating age to individual job performance (Ng and Feldman, 2008).

The difficulties experienced by unemployed older populations remain partly hidden behind a façade of high job protections enjoyed by many long-term employed older workers and their still relatively lower exposure to unemployment compared to younger age groups. Older workers benefit from last-in/first-out rules, they are covered by open-ended contracts, and seniority-weighted redundancy payments limit their layoffs in many cases. Wage subsidies or layoff taxes imposed on firms in some countries also aim to protect this category of workers. Over-representation of older workers in protected sectors such as public administration, health and education is another factor potentially diminishing their risk of job loss (Schnalzenberger and Winter-Ebmer, 2009; Beckes-Gellner and Schneider, 2012; Eurofound, 2012).

In addition, the outflows of older workers from employment usually do not lead to proportional increases in the numbers of unemployed, as a fraction of this outflow represents direct withdrawals. All this contributes to the still relatively lower incidence of job separations followed by unemployment in this age category (Elsby et al., 2011; Eurofound, 2012). However, this alone tells us little about the nature of unemployment among older workers. Their job-finding chances once unemployed and incidences of long-term unemployment really matter.

Most of the literature does not compare the unemployment durations and job-finding probabilities of older individuals with those of other age groups. Instead, it examines their reemployment probability in the light of the competing 'hazard' of retirement. In this settings, the older individual's decision is made with respect to expected lifetime utility: if their 
job-finding prospects and/or future employment stability/quality are perceived as less favourable, then the (early) retirement decision becomes more attractive and vice versa. The results confirm that increasing the statutory (early) retirement age and/or cuts in the length of provision of unemployment benefits significantly increase the reemployment probability of older individuals (Tatsiramos, 2010; Giesecke and Kind, 2013; Kyyrä and Pesola, 2017).

Studies explicitly comparing the labour market perspectives of older and prime-age population concentrate on various issues. Elsby et al. (2011) explore the British Labour Force Survey and report the job-finding rates of older unemployed workers as being remarkably lower than those of their prime-aged counterparts. Deelen et al. (2018) use Dutch administrative data and examine the effects of firm bankruptcies on employment perspectives of older and prime-age workers. They find a higher adverse impact on older workers. Ichino et al. (2014) assess the reemployment probabilities of older and prime-age workers after a plant closure by using records from the Austrian Social Security Database. They observe higher employment decreases among older workers. Fadejeva and Opmane (2016) study data from the Latvian Labour Force Survey, and report lower hazard ratios of transitioning from unemployment to employment for older unemployed workers.

Hardy et al. (2016) use the European Labour Force Survey to examine the job retention rates of older and prime-age workers (i.e., the shares of workers who hold the same job over the next five years) in the Czech Republic, Hungary, Poland and Slovakia. The retention rates among older workers amount to just half the retention rates among prime-age workers, while the retention rates of older workers increased between 1998 and 2013 only in Poland. Babos and Lubyová (2016) explore the EU-SILC data for Slovakia and find a generally negative impact of age on the job-finding probability for the period 20052009. Flek et al. (2018) use the longitudinal EU-SILC datasets, and establish the presence of considerable gaps between the job-finding probabilities of the older and prime-age groups of unemployed individuals in Central Europe over 2009-2012 (amounting to 30\% in Poland, 35\% in the Czech Republic and 50\% in Slovakia, respectively). ${ }^{1}$

We intend to contribute to the existing literature by focusing on the differences in job-finding probabilities between the two age groups after any given length of previous unemployment spell, additionally considering the impacts of explanatory covariates and unobserved heterogeneity. Besides standard socioeconomic and demographic characteristics such as age, gender, education, household size or structure, we assume that

1 The results obtained by Flek et al. (2018) or Elsby et al. (2011) are based on state-dependent Markov chains, and so detect many relevant features of the age-specific labour market dynamics. However, such an approach makes it less feasible to account for the unemployment duration dependence. It is also rather hard to control their results for the impact of explanatory variables other than age. 
an extended unemployment duration affects the job-finding probability, due to related stigmatisation and discouragement effects. Job-finding probability can then be viewed as a diminishing function of unemployment duration, a phenomenon labelled as a "true" negative duration dependence of unemployment (Machin and Manning, 1999).

The longitudinal structure of our data enables us to consider unemployment a time-related process, and the use of a duration model thus represents a natural option. Specifically, we build on discrete-time proportional hazard models (Cox, 1972), which have been further developed especially by Jenkins (1997).

While the international scope is potentially advantageous and less frequent in the literature, it necessitates keeping the analysis relatively simple. Contrary to national administrative datasets, the EU-SILC's sample sizes are much smaller and lack detailed information on longer employment histories, previous job/firm characteristics, workers' involvement in training programmes, etc. Data availability/structure thus represent a considerable limitation of our analysis.

The countries analysed differ in size, GDP fluctuations and labour market performance. Their pension schemes, active labour market policies and entitlement to unemployment benefits also display certain specificities (European Commission, 2014). These factors can cause differences in job-finding probability across the age groups and countries analysed. However, considering the complexity of these contextual factors, we find it less feasible to reflect them explicitly in our cross-country model framework. This clearly represents another limitation of our research. ${ }^{2}$ Therefore, our primary focus is rather on the possible presence of nearly similar results, or at least common trends, which can be observed in spite of the existing national specificities.

\section{Data Organisation and Estimation Strategies}

This analysis explores data from the EU-SILC, which has been collected since 2005. The EU-SILC is an annual survey designed as a four-year rotational panel and is harmonised by Eurostat. For the longitudinal component, it considers a European sample size of around 100,000 households. Individual household members aged 16+ are interviewed annually for four consecutive years. The data contain individual and household characteristics and also self-reported information on individuals' labour market status, stated retrospectively for each month of the previous calendar year. We distinguish employment, unemployment

2 There are only two cross-country econometric studies available to us (Tatsiramos, 2010; Hardy et al., 2016), addressing, from various viewpoints, the specific position of older workers. Most of the related literature typically concentrates on one selected country, where the focus on institutions, policies, and on various performance indicators can be more detailed than in a cross-country framework. 
and inactivity. In order to achieve the highest possible sample sizes, we pool all the datasets available from the longitudinal EU-SILC release of October 2017. The dataset thus consists of longitudinal EU-SILC 2008-2015, and contains eight four-year panels covering the period January 2004-December 2014.

The sample is limited to unemployed individuals aged 35-49 and 50-61 at the beginning of each of the four-year periods, and includes only respondents participating in the survey for four consecutive years who reported at least one unemployment episode. We exclude unemployment spells which terminated in a move into inactivity. Hence, when we refer to "unemployed" individuals, we have in mind only those who cannot (or do not wish to) withdraw from the labour market after job loss. ${ }^{3}$ We also exclude observations involving unemployment status in the first month of each four-year panel, to avoid the inclusion of the left-censored observations with unknown previous unemployment durations.

Unemployment spells in our sample terminate either in a transition into employment or are naturally right-censored if the individual was unemployed in the last month of the observation. Each individual may experience multiple spells. Hence, the unit of analysis ( $N$ in Tables 1-5) is not an individual, but an unemployment spell (including multi-episodes). For the sake of clarity, we sometimes continue to refer to an individual, but this should be interpreted as above.

For hazard estimates, the spells are grouped into intervals of two-month lengths within the first six months of an unemployment episode, when the job-finding probability is presumably the highest, and the identification of the precise unemployment duration associated with the highest job-finding probability requires a detailed breakdown. For the next six months of unemployment duration, this probability is expected to decline, so we consider only two duration intervals, each lasting three months. The last interval represents spells lasting 13-15 months, when job-finding probability is expected to further decline, and may even become statistically insignificant compared to a reference spell of $16-47$ months.

The means of explanatory variables are stated in Table 1 . They include the following characteristics: gender (ref. female) and age dummies (ref. prime-age in a pooled model, and the 50-54 (35-40) reference age band in the model representing older (prime-age)

3 Models designed solely for the group of older unemployed workers typically also involve the transitions from unemployment to inactivity. This is to account for possible sample selection problems, as unemployed individuals who retire may have given up looking for work because of too low job-finding probability. See, e.g., Tatsiramos (2010) for details on these competing risk-hazard models. In our analysis, however, we focus simultaneously on more age groups of unemployed workers. For the sake of simplicity, we prefer to adopt a model involving only those older and prime-age unemployed workers who have remained active on the labour market after job loss. See, e.g., Fadejeva and Opmane (2016) for an analogous estimation strategy. 
workers only). As for gender differences, results would confirm (or reject) the presence of gender-specific patterns affecting the job-finding probability, linked, for instance, with the possibly lower employability of females because of childcare or executing other family-specific duties. Results established for the age variable would indicate the presence (or absence) of a negative signalling effect associated with higher age. ${ }^{4}$ We also consider dummies for secondary and tertiary education (ref. primary education, ISCED 0-2), to test the role of formal human capital in affecting the job-finding probability.

Table 1: Means of explanatory variables

\begin{tabular}{|c|c|c|c|c|c|c|c|c|}
\hline & \multicolumn{2}{|c|}{ AT } & \multicolumn{2}{|c|}{$C Z$} & \multicolumn{2}{|c|}{ PL } & \multicolumn{2}{|c|}{ SK } \\
\hline & older & $\begin{array}{l}\text { prime- } \\
\text { age }\end{array}$ & older & $\begin{array}{l}\text { prime- } \\
\text { age }\end{array}$ & older & $\begin{array}{l}\text { prime- } \\
\text { age }\end{array}$ & older & $\begin{array}{c}\text { prime- } \\
\text { age }\end{array}$ \\
\hline Male & 0.502 & 0.433 & 0.581 & 0.401 & 0.663 & 0.513 & 0.599 & 0.420 \\
\hline Female & 0.498 & 0.567 & 0.419 & 0.599 & 0.337 & 0.487 & 0.401 & 0.580 \\
\hline Age & 55.436 & 43.256 & 55.620 & 43.762 & 55.454 & 44.046 & 55.101 & 44.544 \\
\hline Primary education & 0.267 & 0.217 & 0.178 & 0.134 & 0.205 & 0.123 & 0.117 & 0.054 \\
\hline Secondary education & 0.637 & 0.635 & 0.774 & 0.787 & 0.751 & 0.810 & 0.773 & 0.823 \\
\hline Tertiary education & 0.096 & 0.149 & 0.047 & 0.080 & 0.043 & 0.067 & 0.109 & 0.124 \\
\hline Number of children & 0.086 & 0.851 & 0.097 & 0.643 & 0.263 & 0.878 & 0.162 & 0.645 \\
\hline Number of adults & 2.182 & 2.111 & 2.313 & 2.654 & 2.729 & 3.010 & 3.211 & 3.391 \\
\hline Home owner & 0.436 & 0.234 & 0.755 & 0.589 & 0.941 & 0.920 & 0.907 & 0.807 \\
\hline Owner with mortgage & 0.178 & 0.311 & 0.089 & 0.181 & 0.016 & 0.044 & 0.032 & 0.086 \\
\hline Renter & 0.386 & 0.455 & 0.156 & 0.230 & 0.043 & 0.036 & 0.061 & 0.108 \\
\hline Densely populated & 0.248 & 0.271 & 0.192 & 0.207 & 0.345 & 0.289 & 0.243 & 0.218 \\
\hline Medium-populated & 0.224 & 0.274 & 0.268 & 0.283 & 0.167 & 0.201 & 0.352 & 0.333 \\
\hline Thinly populated & 0.528 & 0.455 & 0.541 & 0.510 & 0.488 & 0.511 & 0.405 & 0.449 \\
\hline N (U spells) & 303 & 914 & 527 & 905 & 623 & 1379 & 247 & 688 \\
\hline
\end{tabular}

Source: Longitudinal EU-SILC 2008-2015 (October 2017 version); authors' computations

4 Health can substantially influence unemployment duration and job-finding probability. Unfortunately, this variable is burdened by high item-nonresponse particularly in the Czech Republic, where it concerns $17 \%$ of older unemployed respondents and $12 \%$ of prime-age unemployed respondents. Therefore, we do not report results involving this variable. 
The number of children up to 15 years of age and the number of adult household members are added to capture the link of these supply-side characteristics with an individual's job-finding effort. Another explanatory variable includes two dummies for ownership of a flat or house, distinguishing between outright owners and owners paying mortgage (ref: paying rent). Compared to unemployed flat renters or those unemployed paying mortgage, unemployed home owners may feel less pushed to search promptly for a job because of a lower financial pressure imposed on their current household budget. ${ }^{5}$

We estimate the impact of living in densely and medium-populated areas on job-finding probability ( $r e f$. thinly populated area), to test whether the more densely populated the living area, the more job opportunities, and thus the higher the job-finding probability. Finally, we include the year dummies. For simplicity, the explanatory variables correspond to the beginning of each unemployment spell, and then remain fixed over the particular unemployment spell.

Our estimation strategy is as follows: First, we do not account for any explanatory variables, and construct survival functions to check whether the survival curves for older unemployed workers land significantly above the analogous functions for the prime-age unemployed (see the survival functions in Figure 1). Tables $2 a$ and $2 b$ then report the mean and median survival times for both groups.

The Kaplan-Meier (Kaplan and Meier, 1958) estimator of the survival function $S(t)$ at any time $t$ bears the form of $\hat{S}(t)=\prod_{j \mid j \leq t} \frac{n_{j}-d_{j}}{n_{j}}$. For our purposes, $n_{j}$ denotes the number of unemployment spells lasting at least $j$ months, and $d_{j}$ the number of unemployment spells transitioning into employment immediately after $j$ months. The survival functions reflect not only the directly observed values, but also the estimates for right-censored observations.

Next, we identify the factors determining an individual's job-finding probability by performing estimates based on the hazard model (see Tables 3-5). This model defines the continuous hazard rate $h_{\theta}(t)$ for a particular unemployment spell $\theta$ as a product of two terms: (i) the baseline hazard $h_{0}(t)$ indicating how the job-finding probability responds to increasing length of an unemployment spell at the baseline levels of explanatory covariates, and (ii) the term describing how this probability is affected by covariates:

$$
h_{\theta}(t)=h_{0}(t) \cdot e^{X(t, \theta)}
$$

5 Owners paying mortgage cannot be distinguished in Austria in the years 2005 and 2006. Potential owners paying mortgage remain instead in the group of outright owners. 
Due to the monthly structure of the data, we adopt the discrete-time proportional hazard (Jenkins, 1997) with the goal of estimating the parameters $\beta_{k}$ and $\gamma_{j}$ in the following formula:

$$
H_{\theta}(j)=1-\exp \left\{-\exp \left[\left(\sum_{k=1}^{l} X_{k}(j, \theta) \cdot \beta_{k}\right)+\gamma_{j}\right]\right\},
$$

where $j$ is the duration interval of interest, and $X_{1}(j, \theta), \ldots, X_{l}(j, \theta)$ are explanatory covariates. The parameters $\gamma_{j}$ represent natural logarithms of the baseline hazard over the relevant interval.

For the sake of better interpretation, the coefficients $\beta_{k}$ and $\gamma_{j}$ are transformed into hazard ratios $(H R)$. The results reported for a vector of explanatory covariates $\left(X_{1}, X_{2}, \ldots, X_{l}\right)$ thus mean $e^{\beta k}$ rather than $\beta_{k}$. Analogously, for each duration interval $j$, the $H R$ represent $e^{\gamma j}$ rather than $\gamma_{j}$. For the duration intervals $\gamma$, statistically significant values of $H R$ higher than one indicate higher job-finding probability relative to the reference unemployment spell (and vice versa if $H R<1$ ). As for the explanatory covariates, $H R>1$ indicates, for instance, a higher job-finding probability of unemployed individuals with tertiary education relative to the reference category of primary-educated unemployed. ${ }^{6}$

\section{Results}

Figure 1 documents that the survival curves are diminishing over most of the analysed time in all the countries. This is because of a gradual accumulation of closed unemployment spells which represent transitions into employment. In all the cases, the survival functions for older unemployed individuals are placed above the functions for their prime-age counterparts, thus indicating that older workers exit unemployment at a slower pace and later than prime-age workers.

The gaps between both survival curves are statistically significant and are generally widening with increasing unemployment duration. Older workers thus face relatively higher exposure to long-term unemployment. ${ }^{7}$ Compared to the prime-age group, older workers are also relatively less likely to find a job after any given length of previous unemployment spell (these results can be derived as (1-the survival rate) from Figure 1).

6 The likelihood ratio tests of gamma variance check for the significance of unobserved heterogeneity. We report results with the so-called gamma frailty only if there is a significant impact of unobserved heterogeneity on the estimation results.

7 Among other messages, Figure 1 evidences the percentages of older (prime-age) unemployed still failing to find a job after one year of unemployment: $27 \%(17 \%)$ for AT, $36 \%(27 \%)$ for CZ, $43 \%(34 \%)$ for PL, and $46 \%$ (34\%) for SK. 
Figure 1: Survival functions for older") and prime-age ${ }^{2)}$ unemployed workers (2004-2014)

Austria

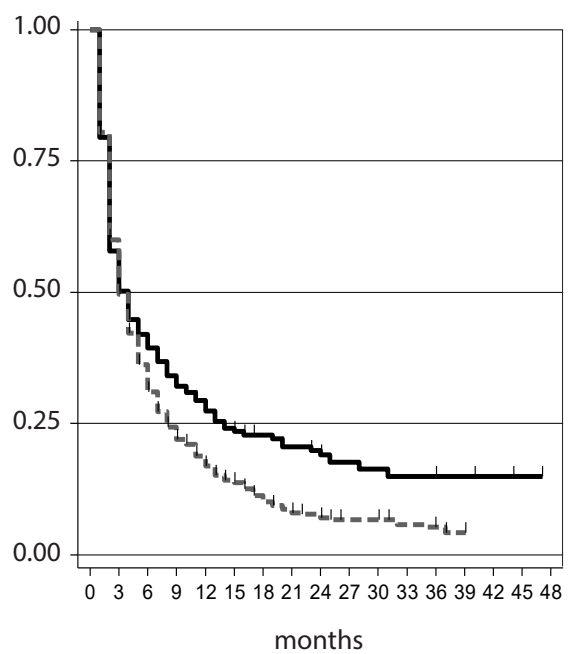

Poland

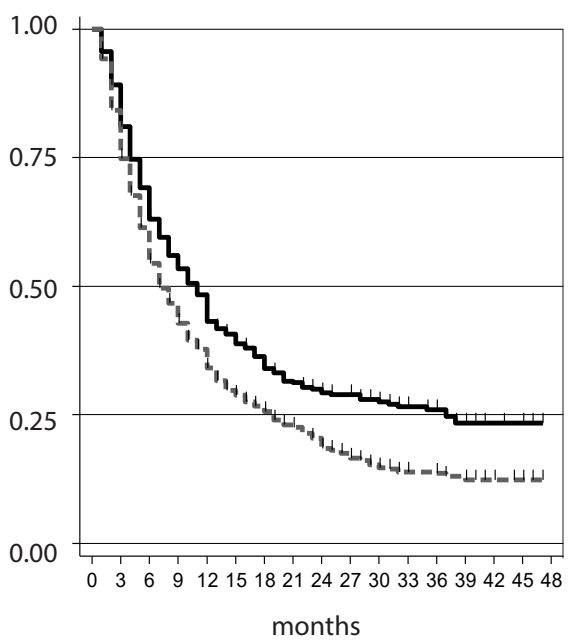

Czech Republic

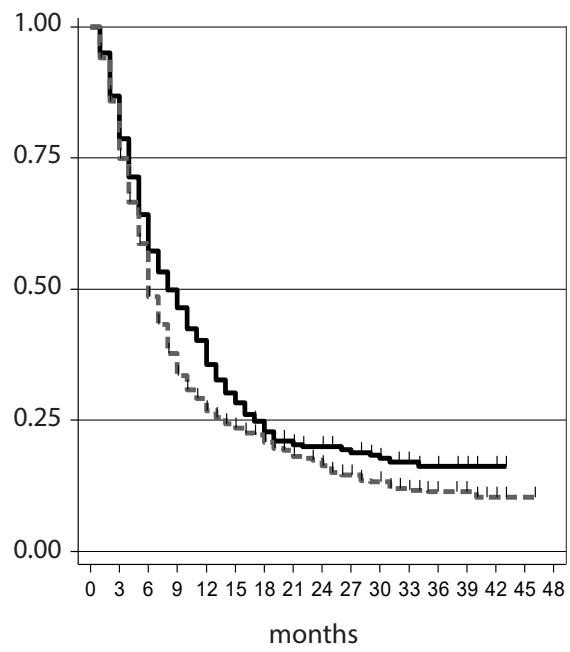

Slovakia

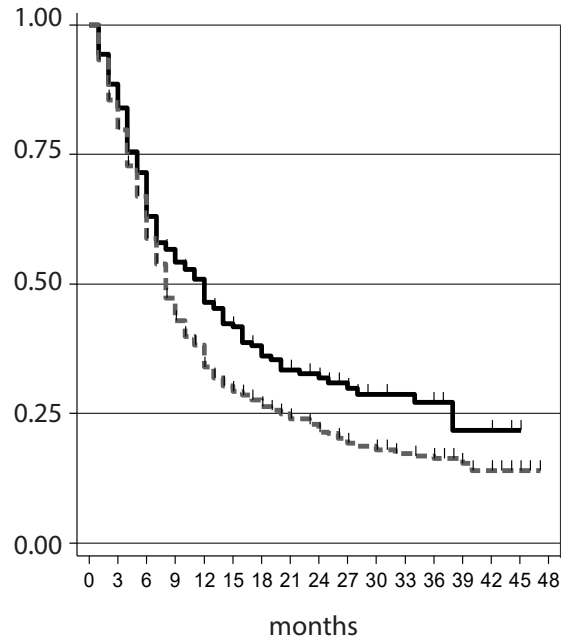

older

$=-n$ " prime-age

Notes: ${ }^{1)}$ Age category $50-61 ;{ }^{2}$ age category $35-49$. The horizontal axes denote the lengths of unemployment spells in months $(t)$, while the vertical axes report the survival rates (i.e., shares of still-open unemployment spells after $t$ months). The log-rank tests uniformly reject the equality of survival functions for older and prime-age unemployed workers at the $1 \%$ level of statistical significance.

Source: Longitudinal EU-SILC 2008-2015 (October 2017 version); authors' computations 
The age-based disproportions in mean and median unemployment durations reported in Tables $2 \mathrm{a}$ and $2 \mathrm{~b}$ considerably disfavour older unemployed workers in all the countries analysed. Note, for instance, that even in Austria and the Czech Republic, where overall unemployment is relatively low, older unemployed workers face median unemployment spells which are one-third higher than those faced by prime-age unemployed workers. In Slovakia and Poland, which have considerably higher unemployment rates, the median unemployment spells of older unemployed workers exceed those of prime-age unemployed workers by $50 \%$ (in Slovakia) or almost $60 \%$ (in Poland).

The key finding reported in Table 3 is that the job-finding probability of older unemployed workers aged $50+$ is about $20-25 \%$ lower than that of the prime-age group. ${ }^{8}$ Furthermore, the hazard ratios point to the prevailing significance of unemployment duration dependence. In most cases, the results also signal an advantageous position of unemployed males compared to unemployed females.

Unemployed individuals living in larger cities appear to be rather disadvantaged in terms of their job-finding probability. The impacts of higher education levels and home ownership are less uniform than one would expect, while the impact of household characteristics is prevailingly insignificant. We intend to interpret these results later in the text, depending on their presence in separate estimates for the older and prime-age groups.

Despite some variations across the countries analysed, the estimation results presented in Table 4 point generally to a negative duration dependence among older unemployed workers: after reaching a certain "threshold" unemployment duration interval with relatively the best job-finding probability, the hazard ratios for longer duration intervals are then either lower (though still significant), or even lose any statistical significance.

In Austria, the relatively best job-finding chances of older unemployed workers are associated with unemployment spells lasting between one and two months $\left(\gamma_{1}\right)$. With increasing unemployment episode duration, the hazard ratios for $\gamma_{2}-\gamma_{5}$ remain at comparatively lower levels, while for the duration interval $\gamma_{6}$ the hazard ratio is statistically insignificant.

8 The results in Table 3 indicate the presence of a slightly lower age-based gap in job-finding probability in Central Europe than in Latvia. For the latter, Fadejeva and Opmane (2016) report a statistically significant hazard ratio 0.68 for the job-finding probability of unemployed workers aged 55+ (relative to the age category of 35-44) over the period 2005-2014. 
Table 2a: Mean and median survival times: prime-age unemployed") (2004-2014, in months)

\begin{tabular}{l|c|c|c|c}
\hline & AT & CZ & PL & SK \\
\hline${\text { Arithmetic mean of completed U spells }{ }^{\text {a) }}}$ & $\begin{array}{c}4.5 \\
(4.8)\end{array}$ & $\begin{array}{c}6.9 \\
(6.0)\end{array}$ & $\begin{array}{c}7.3 \\
(6.4)\end{array}$ & $\begin{array}{c}7.6 \\
(6.6)\end{array}$ \\
\hline Arithmetic mean of all U spells b) $^{\text {b) }}$ & 5.5 & 8.9 & 9.4 & 10.3 \\
\hline Kaplan-Meier restricted mean c) $^{\text {c) }}$ & $(6.4)$ & $(9.0)$ & $(9.1)$ & $(10.0)$ \\
\hline Kaplan-Meier extended mean d) & 7.4 & 12.3 & 13.9 & 14.9 \\
\hline Kaplan-Meier median survival time & $(0.36)$ & $(0.51)$ & $(0.46)$ & $(0.67)$ \\
\hline N - all U spells & 7.9 & 14.4 & 16.7 & 18.3 \\
\hline N - completed U spells & 3 & 6 & 7 & 8 \\
\hline
\end{tabular}

Table 2b: Mean and median survival times: older unemployed ${ }^{2)}$ (2004-2014, in months)

\begin{tabular}{|c|c|c|c|c|}
\hline & AT & $\mathbf{C Z}$ & PL & SK \\
\hline Arithmetic mean of completed U spells ${ }^{\text {a) }}$ & $\begin{array}{c}4.3 \\
(5.1)\end{array}$ & $\begin{array}{c}7.1 \\
(5.6)\end{array}$ & $\begin{array}{c}7.6 \\
(6.4)\end{array}$ & $\begin{array}{c}7.9 \\
(6.7)\end{array}$ \\
\hline Arithmetic mean of all U spells ${ }^{\text {b) }}$ & $\begin{array}{c}7.1 \\
(8.7)\end{array}$ & $\begin{array}{c}9.5 \\
(8.8)\end{array}$ & $\begin{array}{c}11.0 \\
(10.5)\end{array}$ & $\begin{array}{r}11.9 \\
(10.5)\end{array}$ \\
\hline Kaplan-Meier restricted meanc) & $\begin{array}{c}12.1 \\
(1.08)\end{array}$ & $\begin{array}{c}14.2 \\
(0.72)\end{array}$ & $\begin{array}{c}18.6 \\
(0.83)\end{array}$ & $\begin{array}{c}18.6 \\
(1.23)\end{array}$ \\
\hline Kaplan-Meier extended mean d) & 15.8 & 18.0 & 26.2 & 25.0 \\
\hline Kaplan-Meier median survival time ${ }^{\text {e) }}$ & $\begin{array}{c}4 \\
(0.45)\end{array}$ & $\begin{array}{c}8 \\
(0.62)\end{array}$ & $\begin{array}{c}11 \\
(0.67)\end{array}$ & $\begin{array}{c}12 \\
(1.40)\end{array}$ \\
\hline N - all U spells & 303 & 527 & 623 & 247 \\
\hline $\mathbf{N}$ - completed U spells & 224 & 359 & 370 & 150 \\
\hline
\end{tabular}

Notes: ${ }^{1)}$ Age category $35-49 ;{ }^{2)}$ age category 50-61; a) arithmetic means of completed (closed) $U$ spells only; ${ }^{\text {b) }}$ arithmetic means of all unemployment spells observed; c) the area under the survival curve, i.e., also including the estimates for right-censored observations; ${ }^{d)}$ an exponential imputation of the right tail of the survival function so that it eventually reaches zero; ${ }^{\text {e) }}$ computed as the shortest unemployment spell for which the survival function equals or is less than 0.5 (measured in integer months). Standard deviations or standard errors in parentheses.

Source (both tables): Longitudinal EU-SILC 2008-2015 (October 2017 version), authors' computations 
Table 3: Job-finding determinants of unemployed workers: pooled model (2004-2014, hazard ratios)

\begin{tabular}{|c|c|c|c|c|c|}
\hline \multirow[b]{2}{*}{ v1 (1-2 months) } & \multirow{2}{*}{$\begin{array}{c}\text { AT } \\
4.450^{* * *}\end{array}$} & \multicolumn{2}{|c|}{$\mathbf{C Z}$} & \multirow{2}{*}{$\frac{\text { PL }}{2.023^{* * *}}$} & \multirow{2}{*}{$\begin{array}{c}\text { SK } \\
2.191^{* * *}\end{array}$} \\
\hline & & $1.960^{* * *}$ & 0.888 & & \\
\hline Y2 (3-4 months) & $3.048 * * *$ & $3.119^{* * *}$ & 1.559 & $2.824^{* * *}$ & $2.450^{* * *}$ \\
\hline p3 (5-6 months) & $2.404^{* * *}$ & $3.740^{* * *}$ & $2.098^{* *}$ & $2.771^{* * *}$ & $3.115^{* * *}$ \\
\hline Y4 (7-9 months) & $1.906^{* * *}$ & $2.767^{* * *}$ & $1.787^{* *}$ & $2.043^{* * *}$ & $2.860^{* * *}$ \\
\hline ү5 (10-12 months) & $1.417^{*}$ & $2.212^{* * *}$ & $1.619^{* *}$ & $2.102^{* * *}$ & $2.232^{* * *}$ \\
\hline v6 (13-15 months) & 1.236 & $1.561^{* *}$ & 1.271 & $1.414^{* *}$ & $1.521^{*}$ \\
\hline Male & 1.017 & $1.165^{* *}$ & $1.252^{* *}$ & $1.398^{* * *}$ & $1.280^{* * *}$ \\
\hline Older (age $\geq 50$ ) & $0.753^{* * *}$ & $0.791^{* * *}$ & $0.733^{* * *}$ & $0.735^{* * *}$ & $0.830^{*}$ \\
\hline Secondary education & 1.125 & $1.197^{* *}$ & $1.279 * *$ & 1.073 & $1.872^{* * *}$ \\
\hline Tertiary education & 1.140 & $1.339 * *$ & $1.477^{* *}$ & 1.082 & $2.019 * * *$ \\
\hline No. of dependent children & 0.972 & 0.941 & 0.924 & 1.034 & 1.019 \\
\hline No. of adult HH members & 1.055 & 1.009 & 1.008 & $0.944^{* *}$ & 0.991 \\
\hline Home owner & $1.276^{* * *}$ & 1.037 & 1.042 & $0.773^{*}$ & $0.790^{*}$ \\
\hline Owner with mortgage & $1.206^{* *}$ & 1.150 & 1.191 & 0.781 & 1.036 \\
\hline Densely populated area & $0.729 * * *$ & $0.812^{* *}$ & $0.784^{* *}$ & 0.970 & 1.079 \\
\hline Medium-populated area & $0.767^{* * *}$ & $0.878^{*}$ & 0.880 & 0.893 & 1.098 \\
\hline Constant & $0.038^{* * *}$ & $0.027^{* * *}$ & $0.055^{* * *}$ & $0.031^{* * *}$ & $0.011^{* * *}$ \\
\hline Log-Likelihood & $-2,657.500$ & $-3,532.410$ & $-3,530.520$ & $-4,787.380$ & $-2,281.890$ \\
\hline LR test of G var. (p-value) & - & - & 0.026 & - & - \\
\hline N (U spells) & 1,217 & 1,432 & 1,432 & 2,002 & 935 \\
\hline
\end{tabular}

Notes: Age categories 35-49 and 50-61 are pooled; significance codes: ${ }^{* *}=0.01,{ }^{* *}=0.05,{ }^{*}=0.1 ;$ results with gamma frailty are reported only for the Czech Republic in the right column (in the remaining estimates, the impact of unobserved heterogeneity is not statistically significant at the $10 \%$ level); controlled for year dummies. Reference groups of dummy variables are represented by: $U$ spell of 16-47 months; female; prime-age (35-49); primary education; paying monthly rent; thinly populated area.

Source: Longitudinal EU-SILC 2008-2015 (October 2017 version); authors' computations 
Table 4: Job-finding determinants of older unemployed workers (2004-2014, hazard ratios)

\begin{tabular}{|c|c|c|c|c|}
\hline & AT & $C Z$ & PL & SK \\
\hline Y1 (1-2 months) & $8.363^{* * *}$ & $1.892^{* * *}$ & $2.146^{* * *}$ & 1.474 \\
\hline Y2 (3-4 months) & $4.513^{* * *}$ & $2.674^{* * *}$ & $3.362^{* * *}$ & $2.065^{* *}$ \\
\hline p3 (5-6 months) & $2.414^{* *}$ & $3.044^{* * *}$ & $3.260 * * *$ & $2.521^{* * *}$ \\
\hline Y4 (7-9 months) & $2.682^{* *}$ & $1.950 * * *$ & $2.232^{* * *}$ & 1.601 \\
\hline p5 (10-12 months) & $2.108^{*}$ & $2.459^{* * *}$ & $2.761^{* * *}$ & 1.695 \\
\hline v6 (13-15 months) & 1.975 & $2.250 * * *$ & 1.411 & 1.216 \\
\hline Male & 0.966 & 1.136 & $1.478^{* * *}$ & 1.096 \\
\hline Age 55-59 & 1.096 & 0.964 & 0.846 & 1.059 \\
\hline Age $\geq 60$ & $0.469 * *$ & 1.070 & 0.673 & 1.106 \\
\hline Secondary education & $1.570^{* * *}$ & $1.341^{* *}$ & 1.033 & 1.634 \\
\hline Tertiary education & 1.175 & 1.570 & 0.892 & 1.848 \\
\hline $\begin{array}{l}\text { No. of dependent } \\
\text { children }\end{array}$ & 0.943 & 0.939 & 1.074 & 1.239 \\
\hline $\begin{array}{l}\text { No. of adult HH } \\
\text { members }\end{array}$ & 1.105 & 0.936 & 0.937 & 1.000 \\
\hline Home owner & 1.182 & 0.817 & 0.794 & $0.392^{* * *}$ \\
\hline Owner with mortgage & 1.178 & 0.861 & 0.703 & 0.475 \\
\hline Densely populated area & $0.555^{* * *}$ & $0.698^{* *}$ & 0.912 & $1.576^{* *}$ \\
\hline $\begin{array}{l}\text { Medium-populated } \\
\text { area }\end{array}$ & $0.694^{*}$ & 0.946 & 0.989 & 1.391 \\
\hline Constant & $0.012^{* * *}$ & $0.018^{* * *}$ & $0.029 * * *$ & $0.030 * * *$ \\
\hline Log-Likelihood & -618.730 & $-1,256.760$ & $-1,389.180$ & -556.000 \\
\hline N (U spells) & 303 & 527 & 623 & 247 \\
\hline
\end{tabular}

Notes: Age category 50-61; significance codes: ${ }^{* * *}=0.01,{ }^{* *}=0.05,{ }^{*}=0.1$; unobserved heterogeneity is insignificant in all estimated models; controlled for year dummies. Reference groups of dummy variables are represented by: $U$ spell of 16-47 months; female; age 50-54; primary education; paying monthly rent; thinly populated area.

Source: Longitudinal EU-SILC 2008-2015 (October 2017 version), authors' computations

In the Czech Republic and Slovakia, the best job-finding chances of older unemployed workers emerge jointly at 5-6 months of unemployment duration. In Poland, the same effect is associated with unemployment spells lasting 3-4 months. The structure of duration 
dependence among older unemployed workers in the Czech Republic, Poland and Slovakia is thus somewhat different than that in Austria - longer time spent in unemployment is needed in these formerly centrally planned economies to face the "best" job-finding probability. ${ }^{9}$

The stigmatization and/or discouragement effects of prolonged unemployment durations appear to be relatively most pronounced in Slovakia, where the older unemployed workers lack any reasonable chance of finding a job at unemployment durations lasting seven months or more (i.e., starting from $\gamma_{4}$, their job-finding probability is already comparable to those of workers who remain unemployed for an extremely long reference duration interval).

The results of the pooled model in Table 3 point to a relatively favourable job-finding probability of unemployed males compared to unemployed females in most of the countries analysed. However, based on the results presented in Table 4, such a tendency is much less uniform for the older unemployed, and applies rather to gender-based differences in job-finding probability among prime-age unemployed workers (see Table 5).

As for the negative impact of age on the job-finding probability, the hazard ratios in Table 4 point to its significance only in Austria, where this adverse effect begins to apply at 60 years of age. Table 5 involves the effect of higher age on the job-finding probability of prime-age workers, and points to a disadvantage of unemployed workers aged 47+ in Austria and Poland.

Table 4 documents that any significant effect of tertiary education on the job-finding probability is missing among older unemployed workers, while for the prime-age group this effect is significant only in Slovakia (see Table 5). In our opinion, this observation is linked with the existence of segmented or dual labour markets, where unemployed individuals with different education levels normally do not compete for the same jobs. ${ }^{10}$

9 Table 5 reports the hazard ratios for $\gamma 1-6$ within the groups of prime-age unemployed workers. The "threshold" unemployment durations are analogous to those reported for older unemployed workers in Table 4 (except Slovakia).

10 Relatively weak effects of tertiary education on job-finding probability can also be found in the related literature: Giesecke and Kind (2013) apply a wide range of econometric techniques to estimate the determinants of reemployment probability of unemployed workers aged 55-63 in Germany over 1991-2010. The explanatory variables include years of education, and the coefficients are insignificant in all the models applied. Fadejeva and Opmane (2016) estimate the impact of three different types of tertiary education (social sciences, technical sciences, and other) on the job-finding probability of unemployed individuals in Latvia during 2005-2014. They find a significantly positive impact over the whole period investigated (relative to secondary education) only for unemployed workers with a degree in social sciences. In contrast, Babos and Lubyová (2016) report a significantly positive impact of education on the job-finding probability of unemployed individuals in Slovakia in 2005-2009. Our results confirm this finding only for the prime-age fraction of unemployed workers in Slovakia. 
Table 5: Job-finding determinants of prime-age unemployed workers (2004-2014, hazard ratios)

\begin{tabular}{|c|c|c|c|c|c|}
\hline \multirow[b]{2}{*}{ v1 (1-2 months) } & \multirow{2}{*}{$\frac{\text { AT }}{3.156^{* * *}}$} & \multicolumn{2}{|c|}{$C Z$} & \multirow{2}{*}{$\frac{\mathbf{P L}}{1.895^{* * *}}$} & \multirow{2}{*}{$\frac{\text { SK }}{2.395^{* * *}}$} \\
\hline & & $1.937^{* * *}$ & 0.885 & & \\
\hline Y2 (3-4 months) & $2.367^{* * *}$ & $3.292^{* * *}$ & 1.668 & $2.545^{* * *}$ & $2.515^{* * *}$ \\
\hline p3 (5-6 months) & $2.060 * * *$ & $4.070^{* * *}$ & $2.330^{* *}$ & $2.522^{* * *}$ & $3.312^{* * *}$ \\
\hline Y4 (7-9 months) & $1.557^{* *}$ & $3.243^{* * *}$ & $2.175^{* *}$ & $1.931^{* * *}$ & $3.400 * * *$ \\
\hline ү5 (10-12 months) & 1.161 & $1.996^{* * *}$ & 1.529 & $1.842^{* * *}$ & $2.489 * * *$ \\
\hline y6 (13-15 months) & 0.967 & 1.153 & 0.966 & $1.392 *$ & $1.662^{* *}$ \\
\hline Male & 1.081 & $1.193^{* *}$ & $1.302^{* *}$ & $1.4^{* * *}$ & $1.335^{* * *}$ \\
\hline Age 41-46 & 0.913 & 1.124 & 1.194 & 0.998 & 0.879 \\
\hline Age $\geq 47$ & $0.649 * * *$ & 0.969 & 1.034 & $0.866^{*}$ & 0.865 \\
\hline Secondary education & 1.006 & 1.107 & 1.154 & 1.102 & $2.127^{* * *}$ \\
\hline Tertiary education & 1.062 & 1.211 & 1.327 & 1.137 & $2.230 * * *$ \\
\hline No. of dependent children & $0.934^{*}$ & 0.955 & 0.955 & 1.011 & 0.998 \\
\hline No. of adult HH members & 1.033 & 1.036 & 1.041 & $0.947^{*}$ & 0.987 \\
\hline Home owner & $1.344^{* * *}$ & $1.181^{*}$ & 1.198 & 0.782 & 0.883 \\
\hline Owner with mortgage & $1.251^{* *}$ & $1.302^{* *}$ & $1.421^{* *}$ & 0.781 & 1.089 \\
\hline Densely populated area & $0.766^{* * *}$ & 0.904 & 0.888 & 1.003 & 0.939 \\
\hline Medium-populated area & $0.811^{* *}$ & $0.853^{*}$ & 0.841 & 0.867 & 1.015 \\
\hline Constant & $0.069 * * *$ & $0.027^{* * *}$ & $0.051^{* * *}$ & $0.029 * * *$ & $0.006^{* * *}$ \\
\hline Log-Likelihood & $-2,006.120$ & $-2,257.650$ & $-2,256.470$ & $-3,384.920$ & $-1,706.490$ \\
\hline LR test of G var. (p-value) & - & - & 0.062 & - & - \\
\hline N (U spells) & 914 & 905 & 905 & 1,379 & 688 \\
\hline
\end{tabular}

Notes: Age category 35-49; significance codes: ${ }^{* *}=0.01,{ }^{* *}=0.05,{ }^{*}=0.1$; results with gamma frailty are reported only for the Czech Republic in the right column (in the remaining model estimates, the impact of unobserved heterogeneity is not statistically significant at the $10 \%$ level); controlled for year dummies. Reference groups for dummies are represented by: $U$ spell of 16-47 months; female; age 35-40; primary education; paying monthly rent; thinly populated area.

Source: Longitudinal EU-SILC 2008-2015 (August 2017 version), authors' computations

Unemployed workers with tertiary education would typically apply for jobs requiring this education level, i.e., jobs of the highest quality and stability, which are offered on primary labour markets. One may also assume that highly educated unemployed individuals with high reservation wages would be able to accept a longer job-search, 
not responding to "second-rate" job offers. On the demand side, one can in turn expect a relatively high negative signalling effect associated with those unemployed with tertiary education, as their unemployment status may be perceived as less "natural" compared to that of the less educated.

Household size and structure represent relevant supply-side characteristics, with potential impact on the job-finding probability. However, for older unemployed workers, this impact is insignificant in all the cases. Also the impact of home ownership is rather exceptional in this group of unemployed (see Table 4).

The hazard ratios for living in a densely and/or medium-populated areas reported in Tables 4 and 5 are mostly insignificant and/or lower than one. ${ }^{11}$ In larger cities, reservation wages are probably higher, as are the requirements for job quality and stability. Job-seekers in densely populated areas may therefore take more time to find a good quality job. Note also that the density variable depicts the area of residence, and not necessarily the location of the workplace. Thus, it is possible that many less attractive jobs in large cities are actually held by workers commuting from thinly populated areas with fewer job opportunities.

\section{Conclusion}

Survival estimates signal that unemployed workers aged $50+$ are exposed to longer unemployment episodes and face lower job-finding probabilities compared to prime-age unemployed workers. This represents prima facie evidence of the overall presence of stigmatisation and/or discouragement of older unemployed workers, while the age-based gap in job-finding probability increases with longer unemployment durations. However, these findings alone are not sufficiently instructive. More advanced approaches are needed, to detect with a higher accuracy the magnitude of this gap. To our best knowledge, the present paper might represent a first attempt to do so in a cross-country perspective for the Central European region.

The disadvantaged position of older unemployed workers is confirmed by our estimates of hazard models pooled for both age categories. Apart from detecting the impact of unemployment duration on the job-finding probability, they involve the impact of explanatory covariates, and are also controlled for unobserved heterogeneity. The job-finding probability of older unemployed workers is then about 20-25\% lower than that of the prime-age group. It follows that this age-based gap does not vary considerably across the countries analysed.

Separate hazard estimates designed for older/prime-age workers suggest that unemployment duration is the major determinant of their job-finding probability. In spite of this

11 Flek et al. (2015) report analogous results for the young and prime-age groups of unemployed workers in the Czech Republic and Spain in 2007-2010. 
tendency, a longer time spent in unemployment is always needed in the formerly centrally planned economies than in Austria to face the threshold (i.e., the "best") job-finding probability. This concerns particularly the groups of older unemployed workers in the Czech Republic and Slovakia, where such threshold unemployment durations are the longest, namely 4-6 months. In addition, older unemployed workers in Slovakia lack any reasonable chance to find a job immediately after reaching this threshold probability, i.e., starting from the seventh month of unemployment duration.

The impact of explanatory covariates (socioeconomic and demographic characteristics) on the job-finding probability is, in both age categories, relatively less robust and/or less uniform. The absence of any positive impact of tertiary education on the job-finding probability in the group of older unemployed workers is worth noting as a common tendency. The same finding applies, in this age-group, to the missing impacts of various household characteristics.

Given the considerable (and comparable) sizes of the age-based gaps in job-finding probability, none of the countries analysed should be satisfied with their current active labour market policies. The policies should increase, in particular, the degree of specific targeting of those older unemployed workers who find themselves beyond their threshold unemployment durations.

Unemployment of older workers should receive more attention also in the context of population ageing. So far, the primary focus in Europe has been on measures aimed at increasing the number of economically active population (European Commission, 2014). The same is likely to apply to national levels. For instance, the Czech National Action Plan for 2013-2017 (MLSA, 2013) focused on issues such as pension system revision, increasing the motivation for longer employment of pre-retirees, or developing occupational medicine for older workers, while it remained almost silent with regard to the deeply-rooted problems linked with employability of older unemployed workers.

\section{References}

Babos, P., Lubyová, M. (2016). Effect of Labour Code Reform on Unemployment Duration in the Course of Crisis: Evidence from Slovakia. Ekonomický časopis, 64(3), 218-237. Available at: https://www.sav.sk/index.php?lang=en\&doc=journal-list\&part=article_ response_page\&journal_article_no $=12175$

Beckes-Gellner, U., Schneider, M. R. (2012). Economic Crises and the Elderly. Gerontology, 58(2), 188-192, https://doi.org/10.1159/000330065

Blanchard, O. (1999). European Unemployment: The Role of Shocks and Institutions. Roma: Banca d'Italia. 
Cox, D. R. (1972). Regression Models and Life Tables. Journal of the Royal Statistical Society: Series B (Methodological), 34(2), 187-220, https://doi.org/10.1111/j.25176161.1972.tb00899.x

Deelen, A., de Graaf-Zijland, M., van den Berge, W. (2018). Labour Market Effects of Job

Displacement for Prime-age and Older Workers. IZA Journal of Labor Economics, 7(3), 1-30, https://doi.org/10.1186/s40172-018-0063-x

Elsby, M., Smith, J., Wadsworth, J. (2011). The Role of Worker Flows in the Dynamics and Distribution of UK Unemployment. Oxford Review of Economic Policy, 27(2), 338-363, https://doi.org/10.1093/oxrep/grr014

Eurofound (2012). Employment Trends and Policies for Older Workers in the Recession. Luxembourg: Publications Office of the European Union.

European Commission (2014). Population Ageing in Europe. Facts, Implications and Policies. Luxembourg: Publications Office of the European Union.

Fadejeva, L., Opmane, I. (2016). Internal Labour Market Mobility in 2005-2014 in Latvia: The Micro Data Approach. Baltic Journal of Economics, 16(2), 152-174, https://doi.org/10.1080/1406099X.2016.1196872

Flek, V., Hála, M., Mysíková, M. (2015). Duration Dependence and Exists from Youth Unemployment in Spain and the Czech Republic. Economic Research, 28(1), 1063-1078, https://doi.org/10.1080/1331677X.2015.1084239

Flek, V., Hála, M., Mysíková, M. (2018). Nezaměstnanost a věková segmentace trhu práce (Unemployment and Age-based Labour Market Segmentation). Politická ekonomie, 66(6), 709-731, https://doi.org/10.18267/j.polek.1227

Flek, V., Mysíková, M. (2015). Unemployment Dynamics in Central Europe: A Labour Flow Approach. Prague Economic Papers, 24(1), 73-87, https://doi.org/10.18267/j.pep.501

Giesecke, M., Kind, M. (2013). Bridge Unemployment in Germany: Response in Labour Supply to an Increased Early Retirement Age. RWI-Leibnitz Institut für Wirtschaftsforschung. Essen: Ruhr Economic Paper No. 410, https://doi.org/10.2139/ssrn.2246768

Hardy, W., Kiełczewska, A., Lewandowski, P., Magda, I. (2016). Job Retention among Older Workers in Central and Eastern Europe. IBS, Institute for Structural Research. Warsaw: Working Paper No. 11.

Ichino, A., Schwerdt, G., Winter-Ebmer, R., Zweimüller, J. (2014). Too Old to Work, Too Young to Retire? Laboratory for Interdisciplinary Evaluation of Public Policies. Paris: Working Paper No. 27.

Jenkins, S. P. (1997). Sbe17: Discrete Time Proportional Hazards Regression. STATA Technical Bulletin, 7(39), 22-32.

Kaplan, E. L., Meier, P. (1958). Nonparametric Estimation from Incomplete Observations. Journal of the American Statistical Association, 53(282), 457-481, https://doi.org/10.1080/ 01621459.1958 .10501452

Kyyrä, T., Pesola, H. (2017). Long-term Effects of Extended Unemployment Benefits for Older Workers. Institute of Labor Economics. Bonn: IZA Discussion Paper No. 10839. 
Laditka, J. N., Laditka S. B. (2016). Unemployment, Disability and Life Expectancy in the United States: A Life Course Study. Disability and Health Journal, 9(1), 46-53, https://doi.org/10.1016/j.dhjo.2015.08.003

Machin, S., Manning, A. (1999). The Causes and Consequences of Long Term Unemployment in Europe, in Ashenfelter, O., Card, D., eds., Handbook of Labor Economics. Amsterdam: Elsevier, pp. 3089-3139.

Martin, J. (2018). Live Longer, Work Longer: The Changing Nature of the Labour Market for Older Workers in OECD Countries. Institute of Labor Economics. Bonn IZA Discussion Paper No. 11510.

MLSA (2013). National Action Plan Supporting Positive Ageing for 2013-2017 (Národní akční plán podporující pozitivní stárnutí pro období let 2013 až 2017). Prague: Ministry of Labour and Social Affairs of the Czech Republic.

Ng, T. W., Feldman, D. C. (2008). The Relationship of Age to Ten Dimensions of Job Performance. Journal of Applied Psychology, 93(2), 392-423, https://doi.org/10.1037/0021-9010.93.2.392

Phelps, E. (1972). The Statistical Theory of Racism and Sexism. American Economic Review, 62(4), 659-661. Available at: https://www.jstor.org/stable/1806107

Reich, M., Gordon, D. M., Edwards, E. C. (1973). Dual Labor Markets: A Theory of Labor Market Segmentation. American Economic Review, 63(2), 359-365. Available at: https://www.jstor.org/stable/1817097?seq=1\#page_scan_tab_contents

Schnalzenberger, M., Winter-Ebmer, R. (2009). Layoff Tax and Employment of the Elderly. Labour Economics, 16(6), 618-624, https://doi.org/10.1016/j.labeco.2009.08.008

Spence, M. (1973). Job Market Signalling. Quarterly Journal of Economics, 87(3), 355-374, https://doi.org/10.2307/1882010

Tatsiramos, T. (2010). Job Displacement and the Transitions to Re-employment and Early Retirement for Non-Employed Older Workers. European Economic Review, 54(4), 517-535, https://doi.org/10.1016/j.eur oecorev.2009.10.001 